KélVia CRistina de Camargo

Rosane Riberro Figueiredo Alves²

LUCIANO AUGUSTO BAyLÃO'

ANDREA Alves RIBEIRO ${ }^{3}$

Nadja Lindany Alves de Souza Araujo ${ }^{4}$

Suelene Brito do Nascimento Tavares ${ }^{4}$

Sílvia Helena Rabelo dos Santos ${ }^{4}$

Artigo Original

Palavras-chave

Biologia celular

Esfregaço vaginal

Vaginose bacteriana/microbiologia

Candidíase

Vaginite por trichomonas

Keywords

Cell biology

Vaginal smears

Vaginosis, bacterial/microbiology

Candidiasis

Trichomonas vaginitis

\title{
Secreção vaginal anormal: Sensibilidade, especificidade e concordância entre o diagnóstico clínico e citológico
}

\author{
Abnormal vaginal secretion: sensitivity, specificity \\ and concordance between clinical and cytological diagnosis
}

\section{Resumo}

OBJETIVOS: Estimar a prevalência da vaginose bacteriana (VB), candidíase e tricomoníase e comparar os achados do exame físico da secreção vaginal com o diagnóstico microbiológico, obtido pelo estudo citológico do esfregaço vaginal, pelo do método de Papanicolaou. MÉTODOS: Estudo de corte transversal que incluiu 302 mulheres com idade entre 20 a 87 anos, submetidas à entrevista e exame ginecológico para avaliação da secreção vaginal e coleta de esfregaço citológico, no período de junho de 2012 a maio de 2013. Para avaliar a acurácia das características da secreção vaginal em relação ao diagnóstico microbiológico do esfregaço citológico foi empregado as análises de sensibilidade, especificidade, valor preditivo positivo (VPP) e valor preditivo negativo (VPN), com seus respectivos IC95\%. Para avaliar o grau de concordância entre as características clínicas da secreção vaginal e os achados microbiológicos no exame citológico, foi aplicado o índice kappa (k). RESULTADOS: A prevalência da VB, candidíase e tricomoníase foi de 25,5, 9,3 e 2,0\%, respectivamente. A sensibilidade, especificidade, valor o VPP e o VPN das características clínicas da secreção vaginal para o diagnóstico citológico de VB foram de 74, 78,6, 54,3, e 89,9\%, respectivamente. A sensibilidade, a especificidade, o VPP e o VPN das características clínicas da secreção vaginal para o diagnóstico citológico de candidíase foram de 46,4,86,2, 25,5 e de 94\%, respectivamente. $\bigcirc$ grau de concordância entre a avaliação clínica da secreção vaginal e o diagnóstico microbiológico de VB, candidíase e tricomoníase, avaliados pelo índice kappa foi de 0,47, 0,23 e 0,28, respectivamente. CONCLUSÃO: A causa mais frequente de secreção vaginal anormal foi VB. A avaliação clínica da secreção vaginal apresentou sensibilidade, VPP e grau de concordância moderado a fraco, comparado ao diagnóstico microbiológico, o que indica a necessidade de avaliação complementar do achado clínico de secreção vaginal anormal.

Abstract

PURPOSE: To estimate the prevalence of bacterial vaginosis (BV), candidiasis and trichomoniasis and compare the findings of physical examination of the vaginal secretion with the microbiological diagnosis obtained by cytology study of a vaginal smear using the Papanicolaou method. METHODS: A cross-sectional study of 302 women aged 20 to 87 years, interviewed and submitted to a gynecology test for the evaluation of vaginal secretion and collection of a cytology smear, from June 2012 to May 2013. Sensitivity analyses were carried out and specificity, positive predictive value (PPV) and negative predictive value (NPV) with their respective $95 \% \mathrm{Cl}$ were determined to assess the accuracy of the characteristics of vaginal secretion in relation to the microbiological diagnosis of the cytology smear. The kappa index ( $k$ ) was used to assess the degree of agreement between the clinical features of vaginal secretion and the microbiological findings obtained by cytology. RESULTS: The prevalence of BV, candidiasis and trichomoniasis was 25.5, 9.3 and 2.0\%, respectively. The sensitivity, specificity, PPV and NPV of the clinical characteristics of vaginal secretion for the cytological diagnosis of BV were 74, 78.6, 54.3 and 89.9\%, respectively. The sensitivity, specificity, PPV and the NPV of the clinical characteristics of vaginal secretion for the cytological diagnosis of candidiasis were 46.4, 86.2, 25.5 and $94 \%$, respectively. The correlation between the clinical evaluation of vaginal secretion and the microbiological diagnosis of $\mathrm{BV}$, candidiasis and trichomoniasis, assessed by the kappa index, was $0.47,0.23$ and 0.28 , respectively. CONCLUSION: The most common cause of abnormal vaginal secretion was BV. The clinical evaluation of vaginal secretion presented amoderate to weak agreement with the microbiological diagnosis, indicating the need for complementary investigation of the clinical findings of abnormal vaginal secretion.

Correspondência

Kélvia Cristina de Camargo Instituto de Patologia Tropical e Saúde Pública da Universidade rederalde Goís

Rua 235 com $1^{0}$ avenida $s / n$ - Setor Leste Universitário CEP: $74605-050$

Goiânia (GO), Brasil

Recebido

$12 / 10 / 2014$
Instituto de Patologia Tropical e Saúde Pública da Universidade Federal de Goiás - UFG - Goiânia (GO), Brasil.

'Centro de Assistência Integral à Saúde (CAIS) Chácara do Governador, Secretaria Municipal de Saúde de Goiânia - Goiânia (GO), Brasil. 2Departamento de Obstetrícia e Ginecologia, Faculdade de Medicina, Universidade Federal de Goiás - UFG - Goiânia (GO), Brasil. ${ }^{3}$ Departamento de Biomedicina, Pontifícia Universidade Católica de Goiás - Goiânia (GO), Brasil.

4Faculdade de Farmácia, Universidade Federal de Goiás - UFG - Goiânia (GO), Brasil.

Conflito de interesses: não há 


\section{Introdução}

O corrimento vaginal é uma das razões mais comuns para consulta ginecológica e, dentre suas causas mais frequentes, incluem-se a vaginose bacteriana (VB), a candidíase e a tricomoníase, responsáveis, em conjunto por $90 \%$ das secreções vaginais anormais ${ }^{1-4}$.

A VB é a causa mais comum de corrimento vaginal, com prevalência variando de 9 a $41,5 \%$, podendo cursar com corrimento vaginal de odor fétido, ou sem sintomas $^{2,5-7}$. A etiologia é obscura; entretanto, acredita-se que envolva a perda dos lactobacilos, com aumento excessivo de outras bactérias normalmente existentes em pequenas concentrações. A participação de bactérias na VB é complexa e pode incluir mais de 80 gêneros diferentes e milhares de espécies, como Gardnerella vaginalis, Atopobium vaginae, Bacteroides, Prevotella, Mobiluncus, Mycoplasma, Peptostreptococcus, etc. ${ }^{6,8}$. Há evidências de considerável morbidade associada à VB, como maior risco de infecção pós-parto, pós aborto, e pós histerectomia; grávidas apresentam maior risco de parto prematuro ${ }^{3}$. É também considerada fator de risco para aquisição e transmissão do Vírus da Imunodeficiência Humana (HIV), do Vírus Herpes Simples tipo 2 (HSV-2), do gonococo e da clamídia, bem como para o desenvolvimento da Doença Inflamatória Pélvica (DIP) ${ }^{9}$.

Acredita-se que a candidíase acometa aproximadamente três quartos das mulheres adultas em algum período da vida e cerca de metade delas terão dois ou mais episódios. A secreção vaginal na candidíase apresenta aspecto caseoso ou em placas aderentes à mucosa vaginal. O prurido vulvar, em geral intenso, produz escoriações e/ou fissuras superficiais, determinadas por coçadura ${ }^{3,10}$. Embora a incidência de infecção por Trichomonas tenha diminuído nos últimos 20 anos, mais de 7,5 milhões de casos novos desta infecção são relatados a cada ano nos Estados Unidos. A secreção vaginal na tricomoníase apresenta de coloração amarelo-esverdeada e odor fétido. Há queixa de irritação e desconforto vulvar. Há evidências de que esta infestação também seja fator de risco para aquisição do HIV e outras DSTs e esteja associada a efeitos adversos na gravidez, como rotura prematura de membranas, parto prematuro e baixo peso ${ }^{3,10}$.

Vários testes podem ser usados para o diagnóstico das vulvovaginites. Dentre os métodos disponíveis, incluem-se os critérios clínicos descritos por Amsel, para o diagnóstico de VB, que inclui as características clínicas e o exame a fresco da secreção vaginal para identificação das células pista; a avaliação do $\mathrm{pH}$ e o teste do odor ${ }^{11}$. O exame a fresco do conteúdo vaginal também é empregado para identificação de fungos e Trichomonas. A classificação da flora microbiana no esfregaço corado pelo Gram é outro método disponível, descrito por Spiegel em 1983 ${ }^{12}$, modificado por Nugent em $1991^{13}$ e simplificado por Ison e Hay em $2002^{14}$. A cultura pode ser empregada para identificação de fungos e Trichomonas ${ }^{3}$. Além destes, estão disponíveis, atualmente, os testes moleculares para diagnóstico de VB, candidíase e tricomoníase ${ }^{15,16}$. O exame citológico de Papanicolaou também foi avaliado como uma ferramenta para diagnosticar infecções/infestações vaginais e alterações da flora vaginal, devido ao seu uso difundido, facilidade de realização e baixo custo ${ }^{5}$.

O método ideal e de elevada acurácia para o diagnóstico das vulvovaginites é controverso. O padrão ouro, empregado principalmente em pesquisas, é a classificação da flora vaginal, de acordo com os critérios de Nugent, enquanto na clínica de rotina, a recomendação é o emprego dos critérios de $\mathrm{Amsel}^{3,10}$. Apesar desta recomendação, existem evidências de elevadas taxas de erro quando clínicos avaliam os espécimes biológicos a fresco pelo microscópio ${ }^{17}$. Além disso, para avaliação da tricomoníase, o exame a fresco sabidamente é exame de baixa sensibilidade ${ }^{10}$. Por outro lado, há também evidências de que, dentre os critérios de Amsel, avaliados isoladamente, o de maior sensibilidade é a avaliação da descarga vaginal ${ }^{18}$.

A falta de recursos limita implementação de tecnologias da saúde em diferentes contextos. A maioria dos ambulatórios de ginecologia no Brasil não dispõem de microscópio e outros materiais para avaliação das vulvovaginites pelos critérios de Amsel. Por outro lado, o diagnóstico com base em sinais e sintomas é simples, de baixo custo e permite o tratamento imediato. Além disso, pode ser implementado em todos os níveis do sistema de saúde ${ }^{19}$. Apesar dessas vantagens, o diagnóstico com base em sinais e sintomas depende de julgamento subjetivo e não detecta infecções assintomáticas ${ }^{20}$. Por outro lado, o teste de Papanicolaou é procedimento de rotina na avaliação ginecológica periódica, devido ao sucesso na prevenção do câncer do colo uterino e de suas lesões precursoras ${ }^{21}$. Além do rastreio de câncer e de suas lesões precursoras, o teste de Papanicolaou avalia a flora bacteriana, detecta células pista e também outros microorganismos, como fungos e Trichomonas com elevada sensibilidade e especificidade $^{22}$. Trata-se de exame de baixo custo, fácil realização e disponível em virtualmente todos os ambulatórios de ginecologia. Desta forma, o objetivo deste estudo foi comparar os achados do exame físico da secreção vaginal com o diagnóstico microbiológico, obtido pelo do método de Papanicolaou.

\section{Métodos}

Estudo de corte transversal, realizado no período de Junho de 2012 a Maio de 2013. A amostra foi constituída por 302 mulheres com idades entre 20 e 87 anos, referenciadas e atendidas no Ambulatório de Ginecologia 
do Centro de Atendimento Integral a Saúde (CAIS) da Chácara do Governador, em Goiânia, Goiás. Foram excluídas as grávidas, as que apresentavam qualquer tipo de sangramento, as que estavam menstruadas ou com intervalo menor que sete dias do término do ciclo menstrual e as que relataram ter menos de 24 horas da relação sexual. O presente estudo foi aprovado pelo Comitê de Ética e Pesquisa da Universidade Federal de Goiás (UFG) (Protocolo $n^{\circ} 174 / 2011$ ). Todas as participantes leram e assinaram o Termo de Consentimento Livre e Esclarecido.

Todas as participantes responderam a um questionário sobre características sócio demográficas (idade, escolaridade e renda) e foram submetidas a exame ginecológico para avaliação das características da secreção vaginal e coleta de espécime cervicovaginal para realização do esfregaço e exame citológico. As características da secreção vaginal foram observadas por dois avaliadores, anotadas em ficha apropriada e caracterizadas, de forma consensual, em

1. sugestivas de VB se foi observada secreção brancoacinzentada, fluida, com odor fétido, em mucosa vaginal sem sinais flogísticos;

2. sugestiva de candidíase se foi observada secreção brancacenta em placas aderentes à mucosa vaginal hiperêmica;

3. sugestiva de tricomoníase se foi observada secreção amarelo-esverdeada, fluida, bolhosa e fétida, em mucosa vaginal hiperêmica e friável.

O material da ectocérvice e endocérvice foi coletado com da espátula de Ayre e escova citológica para confecção do esfregaço citológico, sendo imediatamente fixado. Os esfregaços foram analisados por dois citologistas, com microscopia óptica e aumento de 40 vezes. As amostras foram consideradas satisfatórias quando apresentavam pelo menos de 8.000 a 12.000 células epiteliais e, no mínimo, 10 células endocervicais e/ou metaplásicas. Desconsideraramse amostras insatisfatórias, se houvesse mais de $75 \%$ de células obscurecidas. Os esfregaços foram submetidos a um rigoroso controle de qualidade, adotado pelo referido laboratório, realizado através da pré-escrutínio de todos os esfregaços negativos para anormalidades citológicas cervicais $^{23}$. A adequabilidade das amostras e o grau de anormalidades citológica foram analisados por dois citologistas em duplo cego, e interpretados de acordo com o Sistema de Bethesda, revisado em 2001 ${ }^{21}$.

Os achados microbiológicos foram categorizados de forma consensual em

1. flora lactobacilar normal quando mais de $50 \%$ dos bacilos adquiriram a coloração azul ou cinza, pela técnica de Papanicolaou ${ }^{24}$; em

2. VB quando havia depleção dos lactobacilos, predomínio de cocobacilos e pelo menos $20 \%$ de células indicadoras por campo ${ }^{25}$; em
3. candidíase quando havia leveduras e pseudohifas de coloração eosinofílicas marrom-acinzentadas ${ }^{21}$ e em

4. tricomoníase pelo encontro de estruturas piriformes com flagelos, contendo núcleo de localização excêntrica e tamanho comparável ao dos leucócitos ${ }^{21}$.

As amostras foram analisadas no Centro de Análises Clínicas Rômulo Rocha da Faculdade de Farmácia, Universidade Federal de Goiás.

Foi realizada análise descritiva das características sócias demográficas e calculada a prevalência da VB, candidíase e tricomoníase com seus respectivos IC95\%. Para avaliar a acurácia das características da secreção vaginal em relação ao diagnóstico microbiológico do esfregaço citológico corado pela técnica de Papanicolaou foram empregadas as análises de sensibilidade, especificidade, valor preditivo positivo e valor preditivo negativo, com seus respectivos IC95\%. Foi considerada sensibilidade à capacidade das características clínicas da secreção vaginal em identificar corretamente aquelas portadoras de VB, de candidíase e de tricomoníase; especificidade foi considerada a capacidade das características clínicas da secreção vaginal identificar corretamente as mulheres sem VB, sem candidíase e sem tricomoníase.

Para avaliar o grau de concordância entre as características clínicas da secreção vaginal e os achados microbiológicos no exame citológico, foi aplicado o índice kappa (k) $(\mathrm{k}=\mathrm{Po}-\mathrm{Pe} / 1-\mathrm{Pe}$, sendo Po a proporção de concordâncias observadas e Pe a proporção de concordâncias esperadas). Foram considerados os valores de $\mathrm{k}<0,00$ : ruim; $0,00 \mathrm{a}$

Tabela 1. Características epidemiológicas e de exame ginecológico das 302 participantes

\begin{tabular}{|c|c|c|}
\hline \multirow{2}{*}{ Variáveis } & \multicolumn{2}{|c|}{ Valores } \\
\hline & n & $\%$ \\
\hline \multicolumn{3}{|l|}{ Idade (anos) } \\
\hline Variação & \multicolumn{2}{|c|}{$20-87,0$} \\
\hline Média (DP) & \multicolumn{2}{|c|}{$40,6(13,8)$} \\
\hline \multicolumn{3}{|l|}{ Renda } \\
\hline S1 salário mínimo & 173 & 57,3 \\
\hline >1 salário mínimo & 129 & 42,7 \\
\hline \multicolumn{3}{|l|}{ Escolaridade } \\
\hline Até Ensino Fundamental & 125 & 41,4 \\
\hline Ensino Médio & 144 & 47,7 \\
\hline Ensino Superior & 33 & 10,9 \\
\hline \multicolumn{3}{|c|}{ Achado microscópico em esfregaço citológico } \\
\hline Vaginose bacteriana & 77 & 25,5 \\
\hline Candidiase & 28 & 9,3 \\
\hline Tricomoníase & 6 & 2,0 \\
\hline \multicolumn{3}{|c|}{ Características clínicas da secreção vaginal } \\
\hline Sugestiva de vaginose bacteriana & 105 & 34,8 \\
\hline Sugestiva de candidíase & 50 & 16,6 \\
\hline Sugestiva de tricomoníase & 1 & 0,3 \\
\hline
\end{tabular}


0,20: fraco; 0,21 a 0,40: regular; 0,41 a 0,60 : moderado; 0,61 a 0,80 : substancial; 0,81 a 0,99 : quase perfeito.

\section{Resultados}

A Tabela 1 descreve as características das 302 participantes incluídas no estudo. A idade das participantes variou de 20 a 87 anos, com média de 40,6 anos e desvio padrão de 13,8 . A maioria das participantes (52\%) encontrava-se em idade reprodutiva. A renda individual de até um salário mínimo foi a mais frequente $(57,3 \%)$; $47,7 \%$ das participantes haviam concluído o ensino médio. A prevalência de VB, de candidíase e de tricomoníase, avaliada pelo exame citológico de Papanicolaou foi de 25,5\% (IC95\% 20,8-30,6), 9,3\% (IC95\% 6,3-12,9) e 2,0\% (IC95\% 0,80-4,0), respectivamente. Por outro lado, as características clínicas da secreção vaginal sugestivas de VB, candidíase e tricomoníase foram identificadas em 34,8,16,6 e 0,3\% das participantes, respectivamente (Tabela 1 ).

A Tabela 2 mostra a sensibilidade (taxa de verdadeiramente positivos), a especificidade (taxa de verdadeiramente negativos), o valor preditivo positivo (proporção de doentes, dentre os positivos para o teste), o valor preditivo negativo (proporção de sadios, dentre os negativos para o teste), e o grau de concordância ajustado pelo índice kappa, entre as características clínicas da secreção vaginal e os achados microscópicos em esfregaços citológicos corados pela técnica de Papanicolaou nas 302 participantes.

A sensibilidade, a especificidade, o valor preditivo positivo e o valor preditivo negativo das características clínicas da secreção vaginal para o diagnóstico citológico de VB foram de $74 \%$ (IC95\% 63,3-82,5), 78,6\% (IC95\% 72,9-83,5), 54,3\% (IC95\% 44,8-63,4) e 89,9\% (IC95\% $84,8-93,3)$, respectivamente; por outro lado, a sensibilidade, a especificidade, o valor preditivo positivo e o valor preditivo negativo das características clínicas da secreção vaginal para o diagnóstico citológico de candidíase foram de 46,4\% (IC95\% 29,5-64,2), 86,2\% (IC95\% 81,5-89,7), $25,5 \%$ (IC95\% 15,6-38,9) e 94\% (IC95\% 90,4-96,3), respectivamente (Tabela 2 ).

A análise da sensibilidade, especificidade e valor preditivo para tricomoníase foi prejudicada pela baixa prevalência desta infestação na amostra estudada.

Houve um grau de concordância moderado $(\mathrm{k}=0,47$; IC95\% 0,36-0,58) entre a observação clínica e o diagnóstico citológico de VB. A concordância entre a observação clínica e os diagnósticos citológicos de candidíase $(\mathrm{k}=0,23$, IC95\% 0,13-0,34) e tricomoníase $(\mathrm{k}=0,28$, IC95\% 0,20-0,36), foi regular (Tabela 2).

Tabela 2. Avaliação da sensibilidade, especificidade, valor preditivo positivo e grau de concordância entre as características clínicas da secreção vaginal e os achados microscópicos em esfregaços citológicos corados pela técnica de Papanicolaou em 302 mulheres atendidas em ambulatório de ginecologia

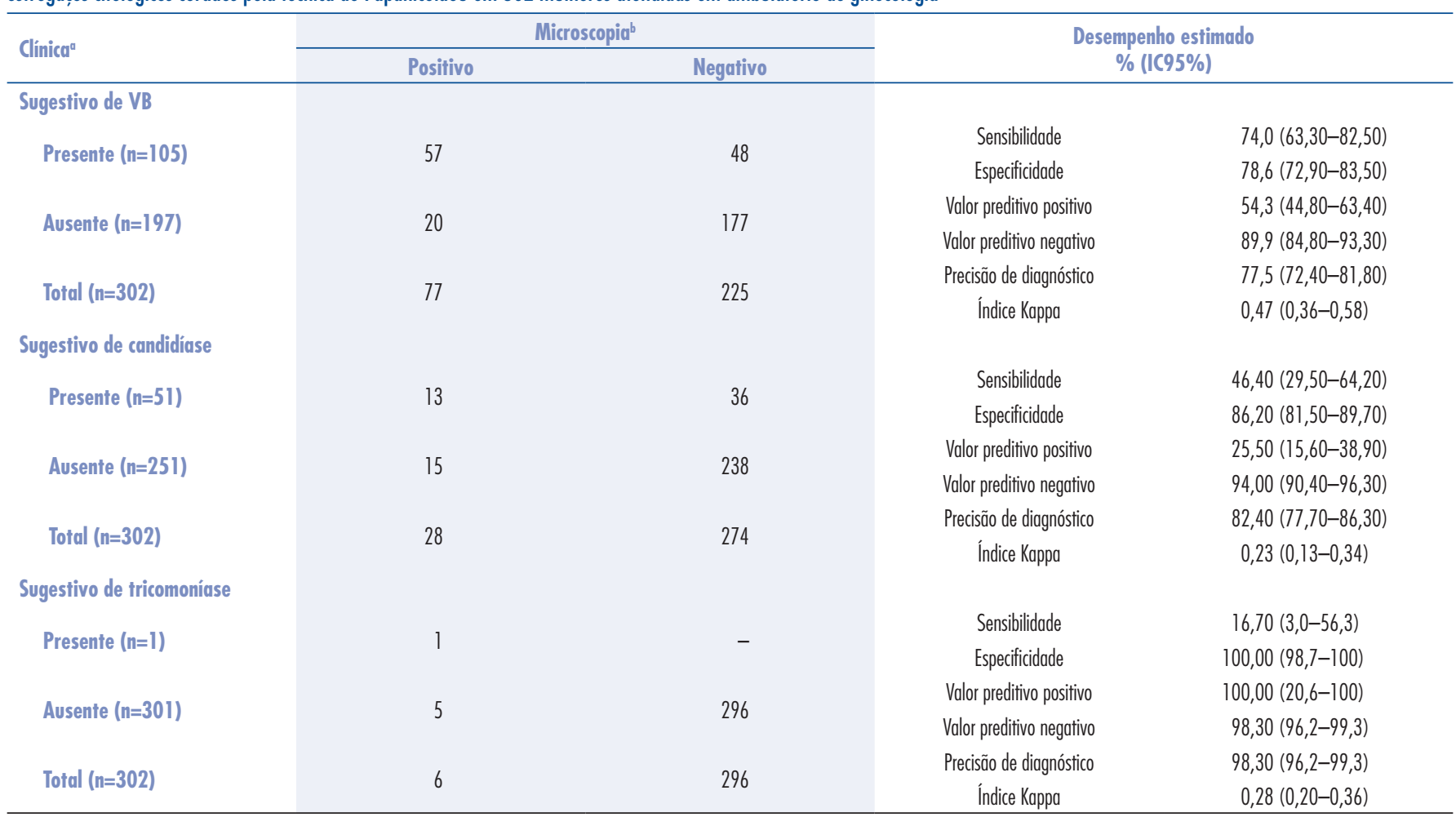

'Característica clínica da secreção vaginal; bAchado microscópico em esfregaço citológico; VB: Vaginose bacteriana; IC95\%: Intervalo de confiança de 95\%. 


\section{Discussão}

O presente estudo avaliou a acurácia do diagnóstico das vulvovaginites com base nos sinais clínicos da secreção vaginal, em 302 mulheres atendidas em ambulatório de ginecologia. O padrão ouro de comparação foi considerado o exame do esfregaço citológico corado pela técnica de Papanicolaou. Enquanto aproximadamente metade da amostra avaliada no presente estudo apresentava secreção vaginal anormal ao exame clínico, em apenas 34,8\% foi encontrado anormalidade da flora bacteriana, fungos elou Trichomonas no exame citológico. A causa mais frequente de secreção vaginal anormal foi VB, seguida pelo encontro de fungos e Trichomonas no esfregaço citológico. A prevalência da VB e da candidíase foi elevada, como já relatado em estudos anteriores ${ }^{1,3,5,7,26}$. Por outro lado, a prevalência da trichomoníase foi baixa, se comparada à população de região de elevada prevalência de infecções de transmissão sexual ${ }^{20}$.

O esfregaço citológico corado pela técnica de Papanicolaou é amplamente utilizado para triagem do câncer cervical e de suas lesões precursoras. Outro benefício é a possibilidade de identificação de microorganismos, da flora bacteriana, como também de células pista. Consequentemente, fornece espécime acessível e de grande utilidade para o diagnóstico de VB, candidíase e trichomoníase. Estudos de validação demonstraram elevada acurácia do exame citológico de Papanicolaou para o diagnóstico de VB, comparado aos critérios de Amsel e ao score de Nugent ${ }^{1,7,27}$.

Neste estudo, a sensibilidade do achado clínico sugestivo de VB, tendo como padrão ouro o estudo do esfregaço citológico de Papanicolaou foi moderada (74\%), achado semelhante a estudos prévios ${ }^{4,18}$. A sensibilidade indica a capacidade do teste diagnóstico ou de triagem identificar corretamente os doentes, e a especificidade, a capacidade de identificação dos sadios ${ }^{28}$. Isto indica que o achado clínico de secreção vaginal branco-acinzentada, fétida em mucosa sem sinais flogísticos pode identificar esta alteração da flora vaginal em uma proporção considerável de mulheres. Todavia, também demonstra que a avaliação das características clínicas da secreção vaginal anormal é subjetiva e pode não identificar aproximadamente um terço das mulheres com VB pela citologia, uma vez que a taxa de falso-negativos é elevada. De fato, esta avaliação pode variar com a qualidade da iluminação local, a acuidade visual e a opinião do examinador.

A sensibilidade do exame de Papanicolaou para diagnóstico de VB relatado em estudos prévios varia de 43,1 a $95 \%\left(43,1^{29}, 78,3^{7}\right.$ e $\left.93 \%{ }^{27}\right)$. Esta grande variação reflete o emprego de diferentes critérios morfológicos e do local de coleta, se dupla, do colo e canal ou se foi incluído material coletado do fundo de saco. Em muitos países, a coleta de material para confecção do esfregaço citológico é realizada apenas na ecto e endocérvice. Isto poderia explicar resultados diferentes na acurácia, descrita em outros estudos, conduzidos em países onde a coleta é tríplice, rotineiramente ${ }^{29,30}$. No entanto, recente publicação demonstrou elevada concordância (índice kappa de $0,92)$ entre amostras do colo uterino e da parede vaginal, coradas pela técnica de Papanicolaou e avaliadas por dois investigadores diferentes ${ }^{25}$.

Outro ponto a se considerar na avaliação de resultados discordantes de sensibilidade é que a coloração de Papanicolaou foi desenvolvida especialmente para corar o núcleo da célula epitelial, o que pode explicar sua menor utilidade relatada em outros estudos. No entanto, o emprego de microscópio de contraste de fase melhora a visualização dos morfotipos bacterianos e a acurácia do exame ${ }^{1}$. Por outro lado, a especificidade do exame citológico relatada na literatura para o diagnóstico de alterações na flora vaginal é elevada. O que indica que o exame citológico é um bom critério diagnóstico quando positivo $^{5,25,29}$.

A opção por testes diagnósticos de elevada sensibilidade é feita quando há necessidade de se excluir doenças que apresentem elevados índices de morbidade. Todavia, existem discussões na literatura sobre o valor da triagem e tratamento de mulheres grávidas assintomáticas para $\mathrm{VB}$, com objetivo de diminuir a morbidade neonatal relacionada ao parto prematuro, baixo peso de nascimento e rotura prematura de membranas. Neste caso, confirmada a elevada morbidade neonatal associada à VB, um teste diagnóstico de elevada sensibilidade seria necessário para a triagem. Todavia, em recente atualização da $U S$ Preventive Services Task Force (USPSTF) nenhum benefício foi encontrado para grávidas de baixo ou médio risco com o tratamento da VB assintomática ${ }^{31}$, o que reforça a não necessidade de se privilegiar a sensibilidade, em detrimento da especificidade, neste caso.

Por outro lado, a sensibilidade dos achados clínicos sugestivos de candidíase foi baixa $(46,4 \%)$. Este achado é explicado pelo fato de que uma proporção de mulheres abriga a $C$ andida sp na vagina, sem que esta ocasione uma vulvovaginite micótica. Desta forma, o encontro de fungos no esfregaço citológico, em mulheres assintomáticas e/ou com achados do exame físico normal, não indica a presença da doença induzida pelo fungo.

Já a especificidade dos achados clínicos sugestivos de VB $(78,6 \%)$ e, especialmente, de candidíase $(86,4 \%)$ foi maior que a sensibilidade para ambos. A especificidade indica a capacidade de determinado teste diagnóstico ou de triagem de identificar corretamente os dos sadios ${ }^{28}$. Isto indica que a ausência de sinais clínicos sugestivos de VB e, principalmente, de candidíase apresenta maior capacidade de detectar as mulheres sadias, que a presença 
destes sinais, de detectar as portadoras de alterações da flora vaginal e de vulvovaginite micótica.

O valor preditivo positivo foi baixo para os achados clínicos sugestivo de VB (54,3\%), semelhante a estudo prévio $^{18}$ e, principalmente, para aqueles sugestivos de candidíase $(25,5 \%)$. O valor preditivo positivo indica a proporção de portadores da doença, entre os que apresentaram o teste positivo ${ }^{28}$. Isto poderia indicar que o tratamento com base em achados clínicos isoladamente trataria corretamente apenas metade das mulheres com sinais sugestivos de VB e um quarto daquelas com sinais sugestivos de candidíase. Por outro lado, poderia também indicar uma facilidade maior do teste de Papanicolaou em detectar alterações na flora vaginal, como depleção de lactobacilos, a presença de flora cocobacilar e de células pista, comparada à sua capacidade em detectar fungos.

Neste estudo, o grau de concordância avaliado pelo índice kappa, entre o diagnóstico citológico de VB e de encontro de fungos no esfregaço, foi maior que o esperado pelo acaso, mas, ainda assim, apenas moderado para o achado clínico sugestivo de VB e sofrível para o achado clínico sugestivo de candidíase. O índice kappa constitui um avanço em relação à taxa geral de concordância, por ser um indicador ajustado, que leva em consideração a proporção de concordância não aleatória, ou aquela que ocorre além da esperada pelo acaso ${ }^{32}$.

O diagnóstico de VB e candidíase com base nas características da secreção é simples, de baixo custo e rápido, o que permite tratamento imediato. No entanto, de acordo com os resultados do presente estudo, não apresenta acurácia necessária para se indicar tratamento específico. A escolha do método de diagnóstico requer, além de considerações científicas, considerações sobre o contexto de seu emprego, de facilidade ou complexidade de realização e de custos. A quantificação da flora vaginal em esfregaço corado pelo Gram, de acordo com morfologia e coloração das bactérias presentes, requer considerável tempo e habilidade ${ }^{1,7,25,27}$. Da mesma forma, o emprego dos critérios clínicos descritos por Amsel requer exame físico e numerosos testes, como o exame a fresco do conteúdo vaginal para identificação de microorganismos e células pista, a verificação do $\mathrm{pH}$ vaginal e o teste do odor, realizados no momento do atendimento. Todavia, estes testes, além de demorados, dependem de experiência, de interpretação subjetiva do examinador, o que explicaria as elevadas taxas de falha diagnóstica ${ }^{16,17}$. Além disso, há necessidade de microscópio e reagentes no momento do atendimento, nem sempre disponíveis nos ambulatórios de ginecologia no Brasil.

Uma das limitações do presente estudo é que a acurácia dos achados clínicos da secreção vaginal anormal não foi comparada aos critérios de Amsel, ou à avaliação da flora em esfregaço corado pelo Gram, nem dos atuais testes moleculares. Todavia, como exposto anteriormente, outros estudos relataram elevada acurácia do exame de Papanicolaou na identificação de $\mathrm{VB}^{1,7,25,27}$, não sobrepujando; no entanto, os atuais testes moleculares para detecção de VB, candidíase e tricomoníase ${ }^{33}$.

Desta forma, de acordo com os resultados deste estudo, deve-se considerar que as características clínicas da secreção vaginal anormal não apresentam acurácia para estabelecer diagnóstico e tratamento e que há necessidade de teste diagnóstico adicional para avaliação destas pacientes. Segundo dados de literatura, o exame citológico de Papanicolaou, facilmente disponível e de baixo custo, apresenta acurácia suficiente para o diagnóstico de alterações da flora vaginal.

\section{Referências}

1. Eriksson K, Forsum U, Biørnerem A, Platz-Christensen JJ, Larsson PG. Validation of the use of Pap-stained vaginal smears for diagnosis of bacterial vaginosis. APMIS. 2007; 1 15(7):809-13.

2. Larsson PG, Forsum U. Bacterial vaginosis - a disturbed bacterial flora and treatment enigma. APMIS. 2005;113(5):305-16.

3. Centers for Disease Control and Prevention (CDC). Notifiable diseases and mortality tables. MMWR Morb Mortal Wkly Rep. 2010;59(2):50-63.

4. Ray K, Muralidhar S, Bala M, Kumari M, Salhan S, Gupta SM, et al. Comparative study of syndromic and etiological diagnosis of reproductive tract infections/sexually transmitted infections in women in Delhi. Int J Infect Dis. 2009;13(6):e352-9.

5. Karani A, De Vuyst H, Luchters S, Othigo J, Mandaliya K, Chersich $M F$, et al. The pap smear for detection of bacterial vaginosis. Int J Gynaecol Obstet. 2007;98(1):20-3.
6. Livengood $\mathrm{CH}$. Bacterial vaginosis: an overview for 2009. Rev Obstet Gynecol. 2009;2(1):28-37

7. Sodhani P, Garg S, Bhalla P, Singh MM, Sharma S, Gupta S. Prevalence of bacterial vaginosis in a community setting and role of the pap smear in its detection. Acta Cytol. 2005;49(6):634-8.

8. Ling Z, Kong J, Liu F, Zhu H, Chen X, Wang Y, et al. Molecular analysis of the diversity of vaginal microbiota associated with bacterial vaginosis. BMC Genomics. 2010;11(1):488.

9. Myer L, Kuhn L, Stein ZA, Wright TC Jr, Denny L. Intravaginal practices, bacterial vaginosis, and women's susceptibility to HIV infection: epidemiological evidence and biological mechanisms. Lancet Infect Dis. 2005;5(12):786-94.

10. Centers for Disease Control and Prevention [Internet]. Trichomoniasis. CDC Fact Sheet. 2007 [cited 2015 Mar 13]. Available from: <http:// www.buttecounty.net/publichealth/cder/std_cdc_trichomoniasis_ fact_sheet.pdf> 
11. Amsel R, Totten PA, Spiegel CA, Chen KC, Eschenbach D, Holmes KK. Nonspecific vaginitis. Diagnostic criteria and microbial and epidemiologic associations. Am J Med. 1983;74(1):14-22.

12. Spiegel CA, Amsel R, Holmes KK. Diagnosis of bacterial vaginosis by direct gram stain of vaginal fluid. J Clin Microbiol. 1983;18(1):170-7.

13. Nugent RP, Krohn MA, Hillier SL. Reliability of diagnosing bacterial vaginosis is improved by a standardized method of gram stain interpretation. J Clin Microbial. 1991;29(2):297-301.

14. Ison CA, Hay PE. Validation of a simplified grading of gram stained vaginal smears for use in genitourinary medicine clinics. Sex Transm Infect. 2002;78(6):413-5.

15. Cartwright $C P$, Lembke $B D$, Ramachandran $K$, Body $B A, N y e M B$, Rivers $C A$, et al. Comparison of nucleic acid amplification assays with BD affirm VPIII for diagnosis of vaginitis in symptomatic women. J Clin Microbiol. 2013;51 (1 1):3694-9.

16. Lowe NK, Neal JL, Ryan-Wenger NA. Accuracy of the clinical diagnosis of vaginitis compared to a DNA probe laboratory standard. Obstet Gynecol. 2009; 1 13(1):89-95.

17. Schwiertz A, Taras D, Rusch K, Rusch V. Throwing the dice for the diagnosis of vaginal complaints? Ann Clin Microbiol Antimicrob. 2006;5:4.

18. Simoes JA, Discacciati MG, Brolazo EM, Portugal PM, Dini DV, Dantas MC. Clinical diagnosis of bacterial vaginosis. Int J Gyanecol Obstet. 2006;94(1):28-32.

19. Brasil. Ministério da Saúde. Secretaria de Vigilância em Saúde. Manual de controle das doenças sexualmente transmissíveis. 4a ed. Brasília (DF): Ministério da Saúde; 2006.

20. Ghebremichael $M$. The syndromic versus laboratory diagnosis of sexually transmitted infections in resource-limited settings. ISRN AIDS. 2014;2014:103452.

21. Solomon D, Davey D, Kurman R, Moriarty A, O'Connor D, Prey $M$, et al. The 2001 Bethesda System: terminology for reporting results of cervical cytology. JAMA. 2002;287(16):21 14-9.

22. Loo SK, Tang WY, Lo KK. Clinical significance of Trichomonas vaginalis detected in papanicolaou smear: a survey in female social hygiene clinic. Hong Kong Med J. 2009;15(2):90-3.
23. Tavares SBN, Amaral RG, Manrique EJC, Sousa NLA, Albuquerque ZBP, Zeferino LC. Controle da qualidade em citopatologia cervical: revisão de literatura. Rev Bras Cancerol. 2007;53(3):355-64.

24. Consolaro MEL, Maria-Engler SS. Citologia clínica cérvico-vaginal: texto e atlas. São Paulo: Roca; 2012.

25. Discacciati MG, Simoes JA, Amaral RG, Brolazo E, Rabelo-Santos SH, Westin MC, et al. Presence of $20 \%$ or more clue cells: an accurate criterion for the diagnosis of bacterial vaginosis in Papanicolaou cervical smears. Diagn Cytopathol. 2006;34(4):272-6.

26. Martínez-Martínez W, Calderón-Badía B, Cruz-Lage L. Comparison of diagnostic methods for bacterial vaginosis. Afr J Microbiol Res. 2014;8(12):1360-7.

27. Vardar E, Maral I, Inal M, Ozguder O, Tasli F, Postaci H. Comparison of gram stain and pap smear procedures in the diagnosis of bacterial vaginosis. Infect Dis Obstet Gynecol. 2002; 10(4):203-7.

28. Beaglehole R, Bonita R, Kjellstrom T. Basic epidemiology. Geneva: World Health Organization; 1993.

29. Tokyol C, Aktepe OC, Cevrioglu AS, Altindiş M, Dilek FH. Bacterial vaginosis: comparison of pap smear and microbiological test results. Mod Pathol. 2004;17(7):857-60.

30. Greene JF 3rd, Kuehl TJ, Allen SR. The papanicolaou smear: inadequate screening test for bacterial vaginosis during pregnancy. Am J Obstet Gynecol. 2000; 182(5):1048-9.

31. Nygren $P$, Fu R, Freeman M, Bougatsos C, Klebanoff M, Guise JM; U.S. Preventive Services Task Force. Evidence on the benefits and harms of screening and treating pregnant women who are asymptomatic for bacterial vaginosis: an update review for the U.S. Preventive Services Task Force. Ann Intern Med. $2008 ; 148(3): 220-33$

32. Kraemer HC, Bloch DA. Kappa coefficients in epidemiology: an appraisal of a reappraisal. J Clin Epidemiol. 1988;41 (10):959-68.

33. Levi AW, Harigopal M, Hui P, Schofield K, Chhieng DC. Comparison of affirm VPIII and papanicolaou tests in the detection of infectious vaginitis. Am J Clin Pathol. $2011 ; 135(3): 442-7$. 